\title{
Disinvestment and Value-Based Purchasing Strategies for Pharmaceuticals: An International Review
}

Running Title: Disinvestment and Value-Based Purchasing for Pharmaceuticals

Bonny Parkinson, M.Sc. ${ }^{1}$

Catherine Sermet, M.D. ${ }^{2}$

Fiona Clement, Ph.D. ${ }^{3}$

Steffan Crausaz, B.Pharm., M.Sc., M.B.A ${ }^{4}$

Brian Godman, Ph.D. ${ }^{5}$

Sarah Garner, B.Pharm., Ph.D. ${ }^{6}$

Moni Choudhury, M.Res ${ }^{7}$

Sallie-Anne Pearson, Ph.D. ${ }^{8}$

Rosalie Viney, M.Ec., Ph.D. ${ }^{9}$

Ruth Lopert, B.Med., M.Med.Sc. ${ }^{10}$

Adam G. Elshaug, M.P.H., Ph.D. ${ }^{11}$ * bonny.parkinson@chere.uts.edu.au

sermet@irdes.fr

fclement@ucalgary.ca

steffan.crausaz@pharmac.govt.nz

brian.Godman@ki.se

sarah.Garner@nice.org.uk

moni.choudhury@nice.org.uk

sallie.pearson@sydney.edu.au

rosalie.viney@chere.uts.edu.au

ruth.lopert@gmail.com

elshaug@sydney.edu.au

1. Research Fellow, Centre for Health Economics Research and Evaluation (CHERE), University of Technology Sydney, Sydney, Australia

2. Deputy Director, Institut de recherche et de documentation en économie de la santé (IRDES), Paris, France.

3. Assistant Professor and Director, Health Technology Assessment Unit, Dept. of Community Health Sciences, Institute of Public Health, University of Calgary, Canada

4. Chief Executive, Pharmaceutical Management Agency (PHARMAC), Wellington, New Zealand.

5. Senior Research Scientist, Division of Clinical Pharmacology, Karolinska Institutet, Stockholm, Sweden and Professor, Strathclyde Institute of Pharmacy and Biomedical Sciences, Glasgow, UK

6. Associate Director of R\&D, National Institute for Health and Care Excellence (NICE), London, UK 
7. Analyst, Research and Development, National Institute for Health and Care Excellence (NICE), London, UK

8. Associate Professor, Pharmacoepidemiology and Pharmaceutical Policy Research Group, The University of Sydney, Sydney, Australia.

9. Professor and Director, Centre for Health Economics Research and Evaluation (CHERE), University of Technology Sydney, Sydney, Australia

10. Deputy Director, Pharmaceutical Policy \& Strategy, Center for Pharmaceutical Management, Management Sciences for Health, Arlington, Virginia, USA; Adjunct Professor, Department of Health Policy, George Washington University, Washington, DC, USA

11. Associate Professor, HCF Research Foundation Principal Research Fellow, Director, Value in Health Care Division, Menzies Centre for Health Policy, The University of Sydney, Sydney, Australia; Senior Fellow, Lown Institute, Boston, MA, USA *

\section{*Corresponding author}

\section{(Accepted for publication in PharmacoEconomics)}




\section{Abstract}

Pharmaceutical expenditure has increased rapidly across many OECD countries over the past three decades. This growth is an increasing concern for Governments and other third party payers seeking to provide equitable and comprehensive healthcare within sustainable budgets. In order to create headroom for increasing utilisation, and to fund new high cost therapies there is an active push to 'disinvest' from low-value drugs. The aim of this article is to review how reimbursement policy decision makers have sought to partially or completely disinvest from drugs in a range of OECD countries (UK, France, Canada, Australia and New Zealand) where they are publicly funded or subsidised. We employed a systematic literature search strategy and the incorporation of grey literature known to the authorship team. We canvass key policy instruments from each country to outline: key approaches to the identification of candidate drugs for disinvestment assessment (passive approaches versus more active approaches); Methods of disinvestment and value-based purchasing: de-listing, restricting treatment, price or reimbursement rate reductions, encouraging generic prescribing; Lessons learnt from the various approaches; The potential role of coverage with evidence development, and; The need for careful stakeholder management. Dedicated sections are provided with detailed coverage of policy approaches (with drug examples) from each country. Historically countries have relied on 'passive disinvestment', however due to (i) the availability of new costeffectiveness evidence or (ii) 'leakage' in drug utilisation or (iii) market failure in terms of price competition, there is an increasing focus towards 'active disinvestment'. Isolating low-value drugs that would create headroom for innovative new products to enter the market is also motivating disinvestment efforts by multiple parties, including industry. Historically disinvestment has mainly taken the form of price reductions, especially when market failures are perceived to exist, and restricting treatment to sub-populations, particularly when a drug is no longer considered value for money. There is considerable experimentation internationally in mechanisms for disinvestment and the opportunity for countries to learn from each other. Ongoing evaluation of disinvestment strategies is essential, and ought to be reported in the peer-reviewed literature. 


\section{Key Points for Decision Makers}

- Disinvestment from pharmaceuticals by delisting drugs which are not considered good value for money is rare and poses unique challenges.

- Restricting use to more cost-effective populations/indications is an option but poses the challenge of changing clinical practice.

- Disinvestment by way of reducing prices paid is an option that many governments have explored. The capacity to disinvest through price reduction depends on the monopsony power of the purchaser, the patent life of the drug and the extent of competition in the clinical area.

- Managed entry is an option to facilitate disinvestment through future price negotiations.

- With countries trialling new strategies, evaluation is critical, as is knowledge sharing to support continual effective reform.

\section{Word count}

4,711 text excluding boxes

4,630 text in boxes

9,341 text including boxes 


\section{Introduction}

Pharmaceutical expenditure has increased rapidly across many OECD countries over the past three decades, from around US\$190 per capita in 1990 to US $\$ 497$ per capita in 2012, or around 9.6\% per annum (unadjusted for inflation)[1]. This increase has been driven by factors affecting utilisation, including population ageing, increasing prevalence of chronic diseases, conversion of some diseases from acute to chronic (e.g. HIV and AIDS), relaxation of disease and pre-disease definition thresholds, increased screening for diseases, lifestyle/behavioural changes, and rising patient expectations. Moreover there has been a continued launch of new premium priced drugs[2,3] and the average cost of new drugs has been increasing over time with some, especially new biological drugs, costing many thousand US dollars per patient per year[4].

This growth in expenditure is an increasing concern for Governments and other third party payers seeking to provide equitable and comprehensive healthcare within sustainable budgets, and consequently some countries may choose not to fund new high cost drugs[5, 6]. In order to stabilise expenditure growth, and create headroom for increasing utilisation and to fund new high cost therapies, there is an active push to 'disinvest' from lowvalue drugs. Numerous conceptualisations of disinvestment have been promoted[7] but the core premise would see the "partial or complete withdrawal of health resources from any existing health care practices, procedures, technologies or drugs that are deemed to deliver little or no health gain for their cost, and thus are not efficient health resource allocations" with an explicit view towards reallocation to higher value applications[8].

The aim of this article is to review how reimbursement policy decision makers have sought to partially or completely disinvest from drugs in a range of OECD countries where they are publicly funded or subsidised. The experience in these countries may provide useful examples for other countries considering disinvestment.

This article is divided into two key sections: Section 3 discusses the difference between active and passive disinvestment and some common methods used to identify potential candidate drugs when undertaking active disinvestment. Section 4 discusses some common methods employed by agencies to disinvest in the drugs, including delisting, restricting treatment, price or reimbursement rate reductions, and encouraging generic prescribing. Finally, the key lessons learnt during the review are summarised.

\section{Approach}

Many of the policy tools are used by a range of agencies in various countries; however this paper only reviews disinvestment in France, the United Kingdom, Canada, Australia, and New Zealand. These countries were chosen on the basis of known documented activity in disinvestment. However it is acknowledged that by selecting these countries there is a risk of missing other policy tools which could be used to disinvest in drugs. Lower and middle income countries were not included since the principal goal of the authorities in these countries is to improve access to essential drugs rather than initiate 'disinvestment strategies' $[9,10]$. Overall in lower and middle income countries, health care expenditure accounts for between 13 to $32 \%$ of household expenditures, with one in four poor households in low income countries incurring potentially catastrophic health care expenses when family members become ill [11]. Between $41 \%$ and $56 \%$ of households in these countries spend $100 \%$ of health care expenditures on drugs[11-14]. We did not include Brazil and China, for example, 
because the nature of inappropriate use, including drivers,' is still surfacing in its detail. In Brazil, the government subsidises drugs provided to the population. When certain drugs are not available in the standard list of publically available drugs, patients may sue the state to try and obtain them under the principle of universality and comprehensiveness[15]. In China, hospitals and physicians currently require the profits from drug procurement to sustain them[12, 16-18]. This has resulted in irrational prescribing such as: prescribing of high cost injectable antibiotics and proton pump inhibitors (PPIs) when appreciably cheaper oral formulations would suffice; prescribing of injectable traditional Chinese medicines with limited evidence; and prescribing of expensive originators vs. inexpensive cardiovascular drugs)[17, 19-22].

It is well documented throughout the disinvestment literature[7, 23-25] that traditional literature search strategies in the disinvestment area have very high sensitivity and poor specificity, with search results at a magnitude that is not well targeted nor feasible to manage. In addition there is publication bias resulting in government and payer disinvestment initiatives being absent from public fora. Consequently the pharmaceutical policies discussed in this paper are based those uncovered in a literature search, together with key papers in this field known by the co-authors, and the expert knowledge of the co-authors regarding the policy situation in their country (including grey literature). In Table 1 we outline the search strategy used in support of this review, resulting in almost 5000 English language returns. The subsequent sorting process, and the incorporation of grey literature, is one that relied heavily on the judgement of authors as experts in the field.

\section{Results}

Figure 1 presents the methods used by various agencies to identify potential candidates for disinvestment and the methods used to achieve drug utilisation that is considered value for money.

\subsection{How candidates for assessment and disinvestment are identified}

Passive forms of disinvestment are those which are not reliant on direct intervention by reimbursement policy makers. A drug or brand of drug may be withdrawn from the market by the manufacturer due to commercial reasons or safety concerns by a regulatory authority, such as the US Food and Drug Administration (FDA). For example, benfluorex in France (see Box 1) and rofecoxib in Australia (see Box 4) were disinvested for safety reasons. Alternatively policy makers may rely on market forces to reduce drug prices following patent-expiry and the introduction of competition. They may also rely on clinicians to cease prescribing drugs that are considered less efficacious or have more side effects compared to more recently listed drugs (i.e. 'passive disinvestment'). Situations where drugs are purposely not mentioned in treatment guidelines could also be considered a form of passive disinvestment.

Some policy makers may not consider this process to be sufficiently reliable, or may wish to speed up changes in drug utilisation by using more active forms of disinvestment. In particular, they may pursue active reviews of drugs currently receiving public funding to identify those candidates appropriate for disinvestment (i.e. 'active disinvestment'). In theory, a range of criteria can be, and have been, used to identify candidates for assessment, as outlined by Elshaug et al (2009)[26]:

1. New evidence of safety, efficacy or cost-effectiveness becomes available 
2. Geographic and/or provider variations in prescribing patterns

3. Temporal variations in volume or higher than expected utilisation/above specified restriction limits (i.e. 'leakage')

4. Technology development such that a drug is significantly different from that originally assessed or funded (e.g. changes in dosage, how it is administered, or leakage to the treatment of other indications).

5. Public interest or controversy

6. Consultation or nomination by clinical, nursing, allied health and technical staff, health care administrators and funders (including both public and private health insurance)

7. Assessment of new drugs and disinvestment in the comparator drugs

8. Legacy items (i.e. older drugs that have never had their cost-effectiveness assessed).

9. Evidence becomes available indicating that drug utilisation does not reflect what is considered bestpractice based on treatment guidelines

10. Precedent (i.e. action taken in another jurisdiction spurs action elsewhere)

Table 2 outlines the criteria used to identify candidates for assessment and disinvestment in each country.

\section{$<$ INSERT TABLE 2 HERE $>$}

\section{Identification of potential candidates for disinvestment}

France has a highly proactive record in this area having conducted a comprehensive review of all listed drugs between 2000-2004, thus capturing any legacy items as well as incorporating any new evidence that had become available since the drug had been listed (see Box 1)[27]. This approach is resource intensive and requires a high level of will by many actors, including political will. Undoubtedly a 'spring clean' of this magnitude has the potential for high rates of return in terms of appropriate use and value for money for entrenched formulary programs. In an ideal situation, this policy would require ongoing rolling amalgamation of new evidence as it becomes available to ensure the drugs represent value for money. Reflecting this, the first comprehensive review conducted in France was only the initial phase, with disinvestment processes put in place to ensure ongoing reviews (see Box 1).

The other countries have opted to only consider sub-sets of drugs for review. In the UK the then National Institute for Health and Clinical Excellence (NICE) ${ }^{1}$ piloted a process involving consultation and nomination to identify candidates, but found that many suggestions for delisting were based on "social judgments" rather than evidence of poor clinical or cost-effectiveness (see Box 2)[23]. NICE abandoned the pilot and now relies on identifying candidates for disinvestment through its existing processes. Through its technology assessment and clinical guidelines program NICE identifies candidates for which new evidence has become available, through nomination or conflicts with guidelines, and assessment of new drugs (and directed displacement, or disinvestment, in the comparator). However, Garner and Littlejohns (2011) argued that many treatments in the

\footnotetext{
${ }^{1}$ Now the National Institute for Health and Care Excellence (NICE)
} 
"do not do" database relate to inappropriate use of technologies (e.g. contraindications) and 'experimental' use of technologies outside their indications and evidence base[23].

In Australia and in the Canadian Atlantic provinces reviews of both individual drugs and entire drug classes have been undertaken, some of which have led to disinvestment decisions. In Australia the Pharmaceutical Benefits Advisory Committee (PBAC) may conduct reviews initiated in response to emerging concerns regarding: the quality of use; uncertain clinical or cost-effectiveness; higher than predicted utilisation; and/or international differences (see Box 4)[28]. Similarly in the Canadian Atlantic provinces, reviews may be initiated in response to developments in the scientific evidence, changes in regulatory status or concerns over costeffectiveness or budget impact related to changes in the drug prices or the prices of comparators (see Box 3)[29]. Finally, the Pharmaceutical Management Agency (PHARMAC) in New Zealand identifies candidates where price competition has been made possible as a result of a drug, or its therapeutic equivalent, losing patent protection (see Box 5). Occasionally, PHARMAC also conducts therapeutic group reviews to identify ways of improving the value for money for currently listed drugs.

Note that none of the countries explicitly consider 'geographic or provider variation' despite this approach showing promise elsewhere in identifying red flags of overuse in medical services[30]. In the case of the UK, Garner and Littlejohns (2011) argued that this may be because of a lack of utilisation data, particularly indication specific use and in use in secondary care[23].

\section{$\underline{\text { Criteria for assessing candidates for disinvestment }}$}

When considering which drugs should be subject to disinvestment, Australia, United Kingdom, Atlantic Canada and France all consider the effectiveness and safety of the drug versus any relevant comparators, including any new evidence that has become available. Additionally, PBAC in Australia and NICE in United Kingdom consider the cost of the drug and the cost-effectiveness of the drug versus any relevant comparators. PBAC also considers the impact of drug utilisation in clinical practice on the cost-effectiveness of the drug in clinical practice, especially when usage is broader than that intended (referred to as 'leakage'). For example, a review of treatments for Alzheimer's Disease found that around $60 \%$ of patients who initiate treatment with cholinesterase inhibitors continued treatment past six months, substantially higher than the continuation rates expected from data from clinical trials (15-35\%)[31]. Consequently PBAC concluded that the use of these drugs may not be as cost-effective in clinical practice as initially estimated. In terms of disinvestment decisions, PHARMAC in New Zealand mainly considers costs, as there are alternatives to the drugs considered that can deliver the same or similar health outcomes.

\subsection{Types of disinvestment}

\section{De-listing}

The outcomes of the active disinvestment reviews are mixed. NICE concluded that there were few obvious candidates for complete disinvestment (i.e. delisting), with antibiotics and diagnostics predominating, and to date the reviews conducted by PBAC in Australia have resulted in only one drug being delisted (see Box 4). The Transparency Commission in France initially delisted around half of the candidates considered suitable for disinvestment ( 840 of 1,675 drugs). While many of these decisions were re-evaluated following public pressure, 
over two thirds of the delisting decisions were maintained (525 of 763 drugs) (see Box 1). PHARMAC in New Zealand rarely delists drugs because price reductions are so substantial $(>95 \%)$ that such disinvestment is unnecessary. However it is common for PHARMAC to delist pack options, brands, and formulations (see Figure 2).

There are several reasons why a decision maker may be reluctant to delist a drug:

- Delisting a drug removes its subsidy (or third party payment), thus reducing a patient's ability to pay for the drug, which subsequently restricts clinical autonomy and reduces patient and prescriber choice[8, 24]. For example, the patient may prefer a tablet over an injection, may respond to a drug where treatments with all other drugs have failed, or prefer the adverse event profile of a particular drug.

- Perverse incentives are at play which creates stakeholder opposition to disinvestment from drugs [8]. For example, clinicians may be reluctant to switch from intravenously-administered or other injected chemotherapies to oral presentations if they receive extra payments for injecting a drug or administering it intravenously (e.g. in the US and Australia).

- Disinvestment may render the sunk costs of training and any physical capital investments obsolete ${ }^{2}$.

- Fourth, there may be resistance to changing prescribing behaviours in the face of established clinical training and practice paradigms[8].

- Declining drug prices once listed means that their cost-effectiveness is typically improved over time, which reduces the need to delist a drug wholly.

As a result delisting drugs can be met with pressure from clinicians, patients, industry and the media. Sermet et al (2010) noted that delisting drugs in France had "not been without problems, with both patients and physicians believing some of these products were effective despite a lack of scientific evidence" and there was pressure to re-evaluate the disinvestment decisions from industry[27]. Additionally, because much of the communication about the delisting of drugs focused on their insufficient medical value, patients were led to believe that the drugs were non-effective. Therefore, patients did not understand why drugs not worthy of reimbursement were still worthy to be sold on the over-the-counter market.

\section{$\underline{\text { Restricting treatment }}$}

As outlined above, there are few obvious candidates for total disinvestment (de-listing) based on effectiveness grounds alone (unlike safety). An alternative and more common strategy is identifying subgroups in which an intervention is most clinically and cost-effective and applying restrictions, or tightening existing restrictions, on who may receive treatment.

This approach is commonly used in the UK. For example, in March 2008 NICE recommended the cessation of antibiotic prophylaxis against infective endocarditis for patients undergoing dental procedures and procedures at the following sites: upper and lower gastrointestinal tract, genitourinary tract; and upper and lower respiratory tract[32]. Thus cessation of prophylaxis was not recommended for all types of procedures or for active or

\footnotetext{
${ }^{2}$ For example, funding of diabetes nurses to teach diabetes patients how to self-administer insulin or use an insulin pump.
} 
potential infections. Subsequent to the introduction of the NICE guideline Thornhill et. al. (2011) found a significant $78.6 \%$ reduction $(\mathrm{P}<0.001)$ in prescriptions for antibiotic prophylaxis[33]. Restrictions are also applied in other countries as a form of disinvestment. For example, in France from November $1^{\text {st }} 2014$, clinicians must obtain prior authorization for each treatment initiation of rosuvastatin or ezetimibe. This restriction was introduced in order to avoid the constant growth of patent-protected drugs despite the increasing availability of generics[34].

Drugs may also be subject to 'conditional treatment continuation rules' where treatment is restricted to patients who achieve a certain health outcome[35]. Restricting treatment to sub-groups can be used to minimise the risk of leakage and as an effective form of disinvestment where leakage is detected. For example, in Australia a review of anticoagulant therapies recommended restricting new oral anticoagulants (NOACs) to 'patients unable to tolerate warfarin therapy and/or who are unable to obtain satisfactory international normalised ratio (INR) control despite specific measures'[36]. At time of writing this was yet to be fully implemented so the effectiveness of the approach is not yet known. Similarly in France, a review of four drugs used to treat Alzheimer Disease resulted in two restrictions: 1) limitation of the prescription to one year[37]; and 2) After 6 months, continuation of the treatment for Alzheimer's Disease should be assessed by the prescriber and if the patient responds to the treatment and if there are no adverse effects, the prescription may continue for 6 more months. Beyond one year, the renewal should be decided after consultation with a multidisciplinary team[38].

\section{Price or reimbursement rate reductions}

Many countries use price or reimbursement rate reductions as a form of disinvestment. An exception to this is the UK, which may be due to the limited remit of NICE to force price reductions and reluctance by manufacturers to offer price reductions as drug prices in the UK are referenced by many other European countries[39]. However, there are regulations around transparency to rapidly reduce the price of generics in the UK once available[40, 2]. Note that effective price reductions could also be achieved by applying or tightening risk-share schemes (e.g. price-volume agreements, dose-caps etc).

In France, following the re-evaluation of drugs in terms of their service médical rendu (SMR) rating, the reimbursement rate was reduced. However other countries may not be able to consider this option due to legislation restricting costs borne by patients.

France, Australia and New Zealand have also all use effective monopsony power to create downward pressure on the price of originators and generic drugs. For example, in Australia, price reductions were sought from manufacturers as a result of the proactive cost-effectiveness reviews of treatments for Alzheimers's Disease and bDMARDs[31, 41, 42]. In addition, in order to lower the prices paid for off-patent medicines, Australia and France imposes mandatory price discounts. Australia has also implemented reference pricing, however there is evidence to suggest that the reference pricing system in Australia was not entirely successful at reducing the price paid for generic drugs, and may even contributed to the relatively higher prices compared to overseas[43, 44]. More recently, Australia has introduced 'price disclosure' with early evidence of success[45], although Duckett et. al. (2013) argue that the approach is flawed and that price decreases are likely to slow as manufactures learn how to avoid the impact of price disclosure[46]. In Canada, tools such as reference pricing and price-volume agreements are also commonly used however price negotiation falls to each individual 
province. PHARMAC in New Zealand, uses a broad range of tools to lower prices[47]. While some, such as reference pricing and price-volume agreements, are commonly used around the world, other tools, such as package agreements/bundling and tendering sole supply are relatively uncommon.

\section{Encouraging generic prescribing}

Policies that aim to encourage generic prescribing (i.e. prescribing by international non-proprietary name or INN) can be considered another form of disinvestment as the objective is to replace more expensive originators with less expensive generics. In the UK prices of high volume generics can be as low as $3 \%$ to $12 \%$ of prices pre-patent expiry[40]. Consequently, encouraging generic prescribing (or prescribing off-patent medicines that are considered therapeutically-equivalent to a patented drug) can result in considerable savings without compromising care.

Table 3 outlines the variety of tools used to encouraging prescribing across the countries. All countries have some form of education or awareness campaigns regarding generic prescribing targeting clinicians and patients. For example, in the UK clinicians are taught to prescribe by INN in medical schools and receive academic detailing regarding their generic prescribing patterns[40, 48]. In other countries awareness campaigns may aim to inform clinicians and patients about how originator drugs and generics are similar or encourage them to ask for generics.

In New Zealand PHARMAC limits which drugs are subsidised to a certain brand, which could be the originator or a generic and thus there could be said to be mandatory dispensing of generics when a generic is the only drug subsidised. France has also recently implemented mandatory INN prescribing and dispensing of generic drugs. In Australia since 1994, while it is not mandatory to write prescriptions using INN, pharmacists have been allowed to substitute between originator and generic drugs listed on the PBS even if the prescription specifies a particular brand, unless the prescriber indicates that "brand substitution is not permitted"[49]. In terms of financial incentives, France and the United Kingdom use prescribing targets coupled with some form of financial incentive to encourage generic prescribing by clinicians, while France and Australia provide incentives to pharmacists for dispensing generics.

\subsection{Lessons learnt}

\section{Disinvestment strategies}

In the past countries have relied on 'passive disinvestment', but there is an increasing focus towards 'active disinvestment' whereby countries systematically identify drugs suitable for disinvestment. One key reason why a country may actively disinvest in a given drug is that decision makers have modified their assessment of effectiveness, safety or cost-effectiveness due to the availability of new evidence or due to 'leakage' in drug utilisation. The other key reason is that there may be a failure of the market in that the price of drugs used to treat the same condition (including bioequivalent, biosimilar and therapeutically superior drugs) have not responded to increased competition.

Considering only delisting as a disinvestment strategy may prove unsuccessful in terms of identifying suitable candidates, unpopular among various stakeholders, and potentially inappropriate. Furthermore delisting of drugs risks engendering substitution effects; some which may be anticipated while others unexpected and sometimes 
harmful or expensive. In France, substitution of the delisted drug with a drug from another inadequate therapeutic class was observed after the delisting of expectorants and mucolytics[50]; substitution of phytotherapy used in the treatment of anxiety and insomnia with more expensive and potentially more dangerous psychotropic drugs was observed after the end of phytotherapy reimbursement[51]. Substitution can also take the form of alternative non-pharmaceutical treatments as it was seen after the delisting of phlebotonics in France where an increase of the prescription of support stockings was noticed (Sermet, personal communication).

Consequently policy makers should also consider other forms of disinvestment - including applying or further restricting treatment, applying price or reimbursement rate reductions, and tightening risk-share schemes (e.g. dose-caps). These types of disinvestment strategies are more likely to be acceptable politically; although the threat of delisting a drug makes manufacturers more amenable to accepting these disinvestment strategies.

Policy makers should also be aware that disinvestment in a drug may prove to be temporary and may also depend on the availability of other treatments. For example, in France in 2004 Lamaline ${ }^{\circledR}$, a fixed dose combination of paracetamol, opium and caffeine, was considered to have low therapeutic value and was subjected to a reduction of its reimbursement rate from $65 \%$ to $35 \%$ and later from $35 \%$ to $15 \%$. In 2012 , following a new assessment by the Transparency Commission, its medical value was revised to high and the reimbursement rate was restored to $65 \%[52]$. The reason given was that after the withdrawal of dextropropoxyphen from the market due to safety concerns, this combination was one of the few viable alternatives in the mild opioid class for the treatment of pain.

A paradox exists in that the less control a system has over the entry of new drugs, due to structural, political, or other issues, the more likely it is that poor value for money drugs will be adopted; there will be more sensible opportunities to disinvest by delisting funded products. The problem is that the structural conditions that led to the adoption of those drugs in the first place will also act as strong barriers, resisting the disinvestment process.

\section{Coverage with Evidence Development}

Coverage with Evidence Development (CED) arrangements link population-level payment or reimbursement to prospective data collection[35]. These types of arrangements may be considered when uncertainty regarding the clinical effectiveness, safety or resource use associated with a drug is high, which can be reduced by conducting additional research in the form of a clinical trial or an observational study. There has been considerable interest in CED recommendations by policy makers, patients, manufacturers and researchers in many countries[53-56].

A CED recommendation subject to collecting real-world observational data is a special case of a post-market review. For both CED arrangements and post-market reviews there is a risk that the drug is subsequently found to be not as effective or as cost-effective as initially predicted, however this risk is likely to be higher where a formal CED arrangement was considered necessary. As a result a policy decision maker may wish to disinvest in such a drug. CED can, therefore, create a wedge-effect - a pharmaceutical foot in the door - which introduces challenges for decision makers (principally resistance from clinicians, patients, industry and the media) in the event that the evidence calls for the reversal of interim funding. For example, NICE in the UK in 2002 rejected beta interferons and glatiramer acetate to treat patients with multiple sclerosis on the basis of unfavourable costeffectiveness [57, 58]. Despite the rejection, the UK Department of Health approved the drugs conditional on the 
results of a ten year monitoring study where the price would be adjusted to achieve the original ICER ( $£ 36,000 / \mathrm{QALY})$ if the drugs failed to show benefits consistent with the economic model[59]. In 2009 it was reported that, based on patient registry data collected between 2005-07 and compared to historical control data from London, Ontario, Canada (which was used in the economic model), disease progression was not only worse than predicted, but worse compared to the control group[59, 60]. However to date there does not appear to be an amendment of prices.

\section{$\underline{\text { Stakeholder management }}$}

Haas et al. (2012) noted that disinvestment in drugs creates losses to clinicians, patients, and manufacturers, while any savings from disinvestment may not be realised for some time[24]. Furthermore these savings are dispersed amongst less identifiable parties, such as the funding of drugs for other parties or tax-payers. Hence, 'losers' from a disinvestment decision have a stronger incentive to lobby for the continued funding of a particular drug. Stakeholder management can help diffuse any resulting politics. In particular, communicating with stakeholders upfront and throughout the process regarding: what research is required; what level of evidence is required for continuing funding the drug (i.e. pre-specify levels of effectiveness or costeffectiveness); what are the ramifications of not supplying the evidence required; and what are the alternative uses of funds (e.g. the treatment of other patients).

\section{Conclusion}

In the past, countries have relied on 'passive disinvestment'; however there is an increasing focus towards 'active disinvestment'. The two key reasons why a country may actively disinvest in a given drug are: that decision makers have modified their assessment of their effectiveness, safety or cost-effectiveness due to the availability of new evidence or due to 'leakage' in drug utilisation; and market failure in terms of price competition. Pressures are mounting for countries to consider disinvesting from drugs in the future: to isolate low-value drugs that would create headroom for innovative new products to enter the market; when CED arrangements, increasingly in use, point to the need for a reversal of funding; when findings from post-market reviews reveal questions of safety, lower than expected real-world effectiveness or cost-effectiveness, and/or product leakage. Historically disinvestment has mainly taken the form of price reductions, especially when market failures are perceived to exist, and restricting treatment to sub-populations, particularly when a drug is no longer considered value for money. Complete delisting of drugs has occurred, although this requires sound rationale backed by political will. Throughout this paper we have drawn out the distinction between disinvestment initiatives that are mandatory (e.g. de-listing) those that are incentivised (e.g. dispensing incentives for pharmacists) and those that are merely encouraged (e.g. clinical guidelines). Likewise the distinction between blanket (e.g. encouraging generic prescribing) and targeted (e.g. restricting treatment to subgroups) approaches. Essentially any disinvestment strategy for drugs requires a mix of active and passive methods to identify candidates, agreed criteria for prioritizing/selecting candidates and a mix of mandatory, incentivised and encouragement methods for achieving disinvestment from targeted drugs or blanket drug groups. Policy decision makers ought to ensure that other avenues for disinvesting are pre-identified prior to approval (e.g. price discounts, restrictions) or pre-agree to rebates in order to ensure that the drug is costeffective in the face of new evidence. 


\section{Compliance and Ethical Standards}

\section{$\underline{\text { Funding statement }}$}

This research was funded in part by an Australian National Health and Medical Research Council (NHMRC) Capacity Building Grant (ID 571926) and a NHMRC Centre of Research Excellence in Medicines and Ageing Grant (ID 1060407). Associate Professor Elshaug is supported by the HCF Research Foundation as the HCF Research Foundation Principal Research Fellow, and holds an Australian NHMRC Sidney Sax Fellowship (ID 627061). Associate Professor Sallie-Anne Pearson is a Cancer Institute New South Wales Career Development Fellow (ID: 12/CDF/2-25) and an Australian Health Policy Research Fellow. Dr Fiona Clement is supported by a Harkness/Canadian Foundation for Healthcare Improvement in Health Care Policy and Practice fellowship.

\section{Conflicts of interest}

Bonny Parkinson - none to declare

Catherine Sermet - none to declare

Fiona Clement - none to declare

Steffan Crausaz - none to declare

Brian Godman - none to declare

Sarah Garner is directly employed by the National Institute for Health and Care Excellence (NICE)

Moni Choudhury is directly employed by the National Institute for Health and Care Excellence (NICE)

Sallie-Anne Pearson is a member or the Drug Utilisation Sub-Committee of PBAC. The content of this paper does not reflect the views of the Australian Government Department of Health, the PBAC or its SubCommittees.

Rosalie Viney is a member of the Australian Pharmaceutical Benefits Advisory Committee and its Economics Sub-Committee. The content of this paper does not reflect the views of the Australian Government Department of Health, the PBAC or its Sub-Committees.

Ruth Lopert - none to declare

Adam G. Elshaug receives consulting/sitting fees from Cancer Australia, the Capital Markets Cooperative Research Centre - Health Quality Program, NPS MedicineWise, and the Australian Commission on Safety and Quality in Health Care. 


\section{References}

1. Organisation for Economic Co-operation and Development (OECD). OECD Health Statistics 2014: frequently requested data. OECD, Paris. 2015. http://www.oecd.org/health/health-systems/oecd-health-statistics2014-frequently-requested-data.htm. Accessed 5 January 2015.

2. Godman B, Malmstrom RE, Diogene E, Gray A, Jayathissa S, Timoney A et al. Are new models needed to optimize the utilization of new medicines to sustain healthcare systems? Expert review of clinical pharmacology. 2015;8(1):77-94.

3. Garattini S, Bertele' V, Godman B, Haycox A, Wettermark B, Gustafsson LL et al. Enhancing the rational use of new medicines across European health care systems. European Journal of Clinical Pharmacology. 2008;64(12):1137-8.

4. Memorial Sloan Kettering Cancer Center (MSKCC). Cost of Cancer Drugs. MSKCC, New York. 2015. http://www.mskcc.org/research/health-policy-outcomes/cost-drugs. Accessed 6 January 2015.

5. Dudding A. A bitter pill: 10 drugs you can't have. Sunday Star Times. 30 November 2008; p. pC1-2. 6. Cheema PK, Gavura S, Migus M, Godman B, Yeung L, Trudeau ME. International variability in the reimbursement of cancer drugs by publically funded drug programs. Current oncology. 2012;19(3):e165-76. 7. MacKean G, Noseworthy T, Elshaug AG, Leggett L, Littlejohns P, Berezanski J et al. Health technology reassessment: the art of the possible. International journal of technology assessment in health care. 2013;29(4):418-23.

8. Elshaug AG, Hiller JE, Tunis SR, Moss JR. Challenges in Australian policy processes for disinvestment from existing, ineffective health care practices. Australian and New Zealand Health Policy. 2007;4:23.

9. Seiter A. A practical approach to pharmaceutical policy. World Bank. 2010. http://wwwwds.worldbank.org/external/default/WDSContentServer/IW3P/IB/2010/06/22/000334955 20100622050742/Re ndered/PDF/552030PUB0Phar10Box349442B01PUBLIC1.pdf.

10. Godman B AF, Guerra Júnior AA, Alvarez-Madrazo S , Faridah Aryani MY, Bishop I et al. Initiatives among Authorities to Improve the Quality and Efficiency of Prescribing and the Implications. Jn Pharma Care Health Sys. 2014;1(3):15.

11. Wagner AK, Graves AJ, Reiss SK, Lecates R, Zhang F, Ross-Degnan D. Access to care and medicines, burden of health care expenditures, and risk protection: results from the World Health Survey. Health policy. 2011;100(2-3):151-8. doi:10.1016/j.healthpol.2010.08.004.

12. Barber SL, Huang B, Santoso B, Laing R, Paris V, Wu C. The reform of the essential medicines system in China: a comprehensive approach to universal coverage. Journal of global health. 2013;3(1):010303. doi:10.7189/jogh.03.010303.

13. Li X, Zhang W. The impacts of health insurance on health care utilization among the older people in China. Social science \& medicine (1982). 2013;85:59-65. doi:10.1016/j.socscimed.2013.02.037.

14. Van Minh H, Kim Phuong NT, Saksena P, James CD, Xu K. Financial burden of household out-of pocket health expenditure in Viet Nam: findings from the National Living Standard Survey 2002-2010. Social science \& medicine (1982). 2013;96:258-63. doi:10.1016/j.socscimed.2012.11.028. 
15. Caires de Souza AL, de Assis Acurcio F, Guerra Junior AA, Rezende Macedo do Nascimento RC, Godman B, Diniz LM. Insulin glargine in a Brazilian state: should the government disinvest? An assessment based on a systematic review. Applied health economics and health policy. 2014;12(1):19-32. doi:10.1007/s40258-0130073-6.

16. Sun Q, Santoro MA, Meng Q, Liu C, Eggleston K. Pharmaceutical policy in China. Health affairs (Project Hope). 2008;27(4):1042-50. doi:10.1377/hlthaff.27.4.1042.

17. Li Y, Xu J, Wang F, Wang B, Liu L, Hou W et al. Overprescribing in China, driven by financial incentives, results in very high use of antibiotics, injections, and corticosteroids. Health affairs (Project Hope).

2012;31(5):1075-82. doi:10.1377/hlthaff.2010.0965.

18. Tang S, Tao J, Bekedam H. Controlling cost escalation of healthcare: making universal health coverage sustainable in China. BMC public health. 2012;12 Suppl 1:S8. doi:10.1186/1471-2458-12-s1-s8.

19. Mao W TS, Chen W. Does perverse economic incentive lead to the irrational uses of medicines? Expert Rev Pharmacoeconomics Outcomes Res 2013;13(6):693-96.

20. Reynolds L, McKee M. Serve the people or close the sale? Profit-driven overuse of injections and infusions in China's market-based healthcare system. The International journal of health planning and management. 2011;26(4):449-70. doi:10.1002/hpm.1112.

21. Zeng W, Finlayson AE, Shankar S, Bruyn W, Godman B. Prescribing efficiency of proton pump inhibitors in China: influence and future directions. BMC health services research. 2015;15(1):11. doi:10.1186/s12913014-0638-6.

22. Zeng W, Zhen J, Feng M, Campbell SM, Finlayson AE, Godman B. Analysis of the influence of recent reforms in China: cardiovascular and cerebrovascular medicines as a case history to provide future direction. Journal of comparative effectiveness research. 2014;3(4):371-86. doi:10.2217/cer.14.28.

23. Garner S, Littlejohns P. Disinvestment from low value clinical interventions: NICEly done? Bmj. 2011;343:d4519.

24. Haas M, Hall J, Viney R, Gallego G. Breaking up is hard to do: why disinvestment in medical technology is harder than investment. Australian health review : a publication of the Australian Hospital Association. 2012;36(2):148-52.

25. Polisena J, Clifford T, Elshaug A, Mitton C, Russell E, Skidmore B. Case studies that illustrate disinvestment and resource allocation decision-making processes in health care: a systematic review. International journal of technology assessment in health care. 2013;29(2):174-84.

26. Elshaug AG, Moss JR, Littlejohns P, Karnon J, Merlin TL, Hiller JE. Identifying existing health care services that do not provide value for money. Medical Journal of Australia. 2009;190(5):269-73.

27. Sermet C, Andrieu V, Godman B, Van Ganse E, Haycox A, Reynier JP. Ongoing pharmaceutical reforms in France: implications for key stakeholder groups. Applied health economics and health policy. 2010;8(1):7-24. 28. Australian Government Department of Health (DoH). Post-Market Reviews of Pharmaceutical Benefits Scheme Subsidised Medicines. DoH, Canberra. 2015. http://www.pbs.gov.au/info/reviews/subsidisedmedicines-reviews. Accessed 6 January 2015.

29. Nova Scotia Canada. Nova Scotia Pharmacare. Nova Scotia Canada, Canada. 2015.

http://novascotia.ca/dhw/pharmacare/atlantic-common-drug-review.asp\#AEAC. Accessed 28 January 2015. 
30. Fisher ES, Wennberg DE, Stukel TA, Gottlieb DJ, Lucas FL, Pinder EL. The implications of regional variations in Medicare spending. Part 1: the content, quality, and accessibility of care. Annals of internal medicine. 2003;138(4):273-87.

31. Pharmaceutical Benefits Advisory Committee. PBAC Recommendations from the Post-Market Review of Pharmaceutical Benefits Scheme anti-dementia drugs to treat Alzheimers Disease, Ratified Minutes of the December 2012 Special PBAC meeting, Item 4. Canberra: DoH; December 2012.

32. National Institute for Health and Clinical Excellence (NICE). Prophylaxis against infective endocarditis: antimicrobial prophylaxis against infective endocarditis in adults and children undergoing interventional procedures, Clinical Guideline 64. United Kingdom: NICE; March 2008.

33. Thornhill MH, Dayer MJ, Forde JM, Corey GR, Chu VH, Couper DJ et al. Impact of the NICE guideline recommending cessation of antibiotic prophylaxis for prevention of infective endocarditis: before and after study. British Medical Journal. 2011;342:d2392.

34. Pichetti S, Sermet C, Godman B, Campbell SM, Gustafsson LL. Multilevel analysis of the influence of patients' and general practitioners' characteristics on patented versus multiple-sourced statin prescribing in France. Applied health economics and health policy. 2013;11(3):205-18.

35. Garrison LP, Jr., Towse A, Briggs A, de Pouvourville G, Grueger J, Mohr PE et al. Performance-based risksharing arrangements-good practices for design, implementation, and evaluation: report of the ISPOR good practices for performance-based risk-sharing arrangements task force. Value in health : the journal of the International Society for Pharmacoeconomics and Outcomes Research. 2013;16(5):703-19.

36. Australian Government Department of Health and Ageing (DoHA). Review of Anticoagulation Therapies in Atrial Fibrillation. Canberra: DoHA; 2012.

37. Ordre des pharmaciens. Meddispar, Medicamets a dispensation particuliere, Ebixa 20mg CPR PELL B/28.

2015. http://www.meddispar.fr/Medicaments/EBIXA-20-B-

28/\%28type \%29/name/\%28value\%29/ebixa/\%28cip\%29/3400938740301\#nav-buttons Accessed 28 January 2015.

38. La Haute Autorite de Sante (HAS). Commission de Transparence, Rapport D'evaluation 19 octobre 2011 14 septembre 2011. HAS, France. 2011. http://www.has-sante.fr/portail/upload/docs/application/pdf/201111/rapport_evaluation_mdc_alzheimer_19-10-2011.pdf Accessed 28 January 2011.

39. Remuzat C, Urbinati D, Roiz J, Kornfeld A, Toumi M, editors. PHP15: Overview of external reference pricing systems in Europe. International Society for Pharmacoeconomics and Outcomes Research (ISPOR) 19th Annual International Meeting; 2014; Montreal, QC, Canada.

40. Godman B, Bishop I, Finlayson AE, Campbell S, Kwon HY, Bennie M. Reforms and initiatives in Scotland in recent years to encourage the prescribing of generic drugs, their influence and implications for other countries. Expert review of pharmacoeconomics \& outcomes research. 2013;13(4):469-82.

41. Australian Government Department of Health and Ageing (DoHA). Removal of anakinra (brand name Kineret $\left.{ }^{\circledR}\right)$ from the Pharmaceutical Benefits Scheme. DoHA, Canberra. 25 October 2010. http://www.pbs.gov.au/info/news/2010/10/2010-10-25-Removal_of_Kineret. Accessed 28 November 2014. 42. Pharmaceutical Benefits Advisory Committee. Public summary document: PBAC review of bDMARDs for the treatment of severe active rheumatoid athritis. Canberra: DoHA; December 2009. 
43. Clarke PM, Fitzgerald EM. Expiry of patent protection on statins: effects on pharmaceutical expenditure in Australia. Medical Journal of Australia. 2010;192(11):633-6.

44. Bulfone L. High prices for generics in Australia - more competition might help. Australian Health Review. 2009;33(2):200-14.

45. Australian Government Department of Health and Ageing (DoHA). Summary of claimed prices and brand premiums for 1 April 2012. DoHA, Canberra. 2012. http://www.pbs.gov.au/industry/pricing/eapd/eapd-claimedprices-brand-premiums-1-april-2012.pdf. Accessed 24 August 2012.

46. Duckett S, Breadon P, Ginnivan L, Venkataraman P. Australia's bad drug deal: high pharmaceutical prices. Melbourne: Grattan Institute2013.

47. Morgan S, Hanley G, McMahon M, Barer M. Influencing Drug Prices through Formulary-Based Policies: Lessons from New Zealand. Healthcare policy = Politiques de sante. 2007;3(1):e121-40.

48. Godman B, Wettermark B, van Woerkom M, Fraeyman J, Alvarez-Madrazo S, Berg C et al. Multiple policies to enhance prescribing efficiency for established medicines in Europe with a particular focus on demand-side measures: findings and future implications. Frontiers in pharmacology. 2014;5:106.

49. Beecroft G. Generic drug policy in Australia: a community pharmacy perspective. Australia and New Zealand Health Policy. 2007;4(7).

50. Pichetti S, Sorasith C, Sermet C. Analysis of the impact of removing mucolytics and expectorants from the list of reimbursable drugs on prescription rates: a time-series analysis for France 1998-2010. Health policy. 2011;102(2-3):159-69.

51. Riou Franca L, Vidal C, Bourechak N, Jeunne PL, Deville GS, Massol J. A cohort study of therapeutic prescriptions after the end of phytotherapy drug reimbursement by French Social Security.

Pharmacoepidemiology and drug safety. 2013;22(7):760-8.

52. La Haute Autorite de Sante (HAS). Avis de la Commission de Transparence sur la Lamaline. 23 mai 2012.

HAS, France. 2012. http://www.has-sante.fr/portail/upload/docs/application/pdf/2012-

06/lamaline 23052012 avis_ct11613 ct11197.pdf. Accessed 25 March 2013.

53. Vitry A, Roughead E. Managed entry agreements for pharmaceuticals in Australia. Health policy. 2014;117(3):345-52.

54. Carlson JJ, Sullivan SD, Garrison LP, Neumann PJ, Veenstra DL. Linking payment to health outcomes: a taxonomy and examination of performance-based reimbursement schemes between healthcare payers and manufacturers. Health policy. 2010;96(3):179-90.

55. Stafinski T, McCabe CJ, Menon D. Funding the unfundable: mechanisms for managing uncertainty in decisions on the introduction of new and innovative technologies into healthcare systems. Pharmacoeconomics. 2010;28(2):113-42.

56. Claxton K, Palmer S, Longworth L, Bojke L, Griffin S, McKenna C et al. Informing a decision framework for when NICE should recommend the use of health technologies only in the context of an appropriately designed programme of evidence development. Health technology assessment. 2012;16(46):1-323.

57. National Institute for Health and Clinical Excellence (NICE). Beta interferon and glatiramer acetate for the treatment of multiple sclerosis, technology appraisal guidance, no. 32. United Kingdom: NICE; 2002.

58. Thomas S, Prince A, Humphries C, Smith J, Seymour H, Donaldson T et al. Assessment of interferon-beta and glatiramer for the treatment of multiple sclerosis: Report commissioned by the NHS Health Technology 
Assessment Programme on behalf of the National Institute for Clinical Excellence Newcastle upon Tyne

Northern and Yorkshire Regional Drug \& Therapeutics Centre; 2000.

59. Raftery J. Costly failure of a risk sharing scheme. British Medical Journal. 2010;340:1672.

60. Boggild M, Palace J, Barton P, Ben-Shlomo Y, Bregenzer T, Dobson C et al. Multiple sclerosis risk sharing scheme: two year results of clinical cohort study with historical comparator. British Medical Journal.

2009;339:b4677.

61. National Institute for Health and Care Excellence (NICE). NICE 'do not do' recommendations. NICE, United Kingdom. 2015.

https://www.nice.org.uk/proxy/?sourceurl=http://www.nice.org.uk/usingguidance/donotdorecommendations/ind ex.jsp. Accessed 7 January 2015.

62. Choudhury M, Sharma T, Garner S, Hill-Cawthorne G, editors. Searching for 'do not do' recommendations from NICE guidance: a pilot study. Health Technology Assessment international (HTAi) Annual Meeting; 2012 26 June 2012; Bilbao.

63. Hollingworth W, Chamberlain C. Re: Do NICE's recommendations for disinvestment add up? British Medical Journal. 2011;343:d4519.

64. National Instutute for Health and Care Excellence (NICE). NICE Savings and Productivity and Local Practice Collections. NICE, UK. 2015.

http://www.nice.org.uk/savingsAndProductivity/collection?page=6\&pageSize $=10 \&$ type $=\&$ published $=\&$ impact $=$ \&filter. Accessed 5 January 2015.

65. Pharmaceutical Management Agency (PHARMAC). New Zealand Pharmaceutical Schedule. New Zealand: PHARMAC; October 1996 through October 2014.

66. Chevreul K, Durand-Zaleski I, Bahrami S, Hernández-Quevedo C, Mladovsky P. France: health system review. Health Systems in Transition, European Observatory on Health Systems and Policies. 2010;12(6). 67. La Haute Autorite de Sante (HAS). Définition du service médical rendu (SMR). HAS, France. 2015. http://www.has-sante.fr/portail/upload/docs/application/pdf/definition_smr.pdf. Accessed 28 January 2015. 68. La Haute Autorite de Sante (HAS). Rapport d'activite. HAS, France. 2013. http://www.hassante.fr/portail/upload/docs/application/pdf/2014-06/rapport acitivite has_2013.pdf. Accessed 28 January 2015. 69. La Haute Autorite de Sante (HAS). Avis de la Commission de Transparence sur le Mediator. 10 mai 2006. HAS, France. 2006. ttp://www.has-sante.fr/portail/upload/docs/application/pdf/ct032758.pdf. Accessed 25 March 2013.

70. Weill A, Paita M, Tuppin P, Fagot JP, Neumann A, Simon D et al. Benfluorex and valvular heart disease: a cohort study of a million people with diabetes mellitus. Pharmacoepidemiology and drug safety. 2010;19(12):1256-62. doi:10.1002/pds.2044.

71. European Medicines Agency (EMA). European Medicines Agency recommends new contraindications and warnings for pioglitazone to reduce small increased risk of bladder cancer. 2011.

http://www.ema.europa.eu/docs/en_GB/document_library/Press_release/2011/07/WC500109176.pdf. Accessed 5 January 2015.

72. National Health Service (General Medical Services Contracts) (Prescription of Drugs etc.) Regulations 2004, Schedule 1, (2004). 
73. United Kingdom National Health Service (NHS) National Prescribing Centre. PCT responsibilities around prescribing and medicines management. A scoping and support guide. NHS, United Kingdom. 2003. http://www.npc.nhs.uk/non_medical/resources/pct_responsibilities.pdf. Accessed 5 January 2015.

74. Harris CM, Scrivener G. Fundholders' prescribing costs: the first five years. British Medical Journal. 1996;313(7071):1531-4.

75. Rawlins M. In pursuit of quality: the National Institute for Clinical Excellence. Lancet. 1999;353(9158):1079-82.

76. Ford JA, Waugh N, Sharma P, Sculpher M, Walker A. NICE guidance: a comparative study of the introduction of the single technology appraisal process and comparison with guidance from Scottish Medicines Consortium. British Medical Journal Open. 2012;2(1):e000671.

77. All Wales Medicine Strategy Group (AWMSG). Homepage. AWMSG, Wales. 2015. http://www.awmsg.org/. Accessed 5 January 2015.

78. National Institute for Health and Care Excellence (NICE). NICE technology appraisal guidance. NICE, UK. 2015. https://www.nice.org.uk/About/What-we-do/Our-Programmes/NICE-guidance/NICE-technologyappraisal-guidance. Accessed 17 March 2015.

79. Burke K. NICE may fail to stop "postcode prescribing," MPs told. Bmj. 2002;324(191).

80. McGinn D, Godman B, Lonsdale J, Way R, Wettermark B, Haycox A. Initiatives to enhance the quality and efficiency of statin and PPI prescribing in the UK: impact and implications. Expert review of pharmacoeconomics \& outcomes research. 2010;10(1):73-85.

81. National Institute for Health and Care Excellence (NICE). Quality, Productivity and Prevention (QIPP) programme. NICE, London. 2015. https://www.evidence.nhs.uk/qipp. Accessed 28 January 2015.

82. Martin A, Godman B, Miranda J, Tilstone J, Saleem N, Olsson E et al. Measures to improve angiotensin receptor blocker prescribing efficiency in the UK: findings and implications. Journal of comparative effectiveness research. 2014;3(1):41-51.

83. Godman B, Shrank W, Andersen M, Berg C, Bishop I, Burkhardt T et al. Comparing policies to enhance prescribing efficiency in Europe through increasing generic utilization: changes seen and global implications. Expert review of pharmacoeconomics \& outcomes research. 2010;10(6):707-22.

84. Duerden MG, Hughes DA. Generic and therapeutic substitutions in the UK: are they a good thing? British journal of clinical pharmacology. 2010;70(3):335-41.

85. Ferner RE, Lenney W, Marriott JF. Controversy over generic substitution. Bmj. 2010;340:c2548.

86. Canadian Agency for Drugs and Technologies in Health (CADTH). About the Common Drug Review.

CADTH, Canada. 2015. http://www.cadth.ca/en/products/cdr/cdr-overview. Accessed 28 January 2015.

87. Ontario Citizens' Council. A Report of the Ontario Citizens' Council: Managing the drug formulary. 2011. http://www.health.gov.on.ca/en/public/programs/drugs/councils/report/report 201106.pdf. Accessed 28 January 2015.

88. Alberta Provincial Government. Alberta Drug Benefit List Updated Price Policy, Effective January 13, 2015. 2015. https://www.ab.bluecross.ca/dbl/pdfs/dbl_sec1_prpol.pdf. Accessed 28 January 2015.

89. Sloan C. A history of the Pharmaceutical Benefits Scheme 1947-1992. Canberra: Commonwealth

Department of Human Services and Health; 1995. 
90. Australian National Audit Office. Selected measures for managing subsidised drug use in the Pharmaceutical Benefits Scheme. Audit Report No. 44, 2005-06. Canberra: Australian National Audit Office; 2006.

91. National Health Amendment (Immunisation Program) Act, No. 140, (2005).

92. National Health Act, (1953).

93. Amendment to the National Health Act 1953 Subsection 3(a), (1987).

94. O'Donnell JC, Pham SV, Pashos CL, Miller DW, Smith MD. Health technology assessment: lessons learned from around the world - an overview. Value in health : the journal of the International Society for Pharmacoeconomics and Outcomes Research. 2009;12 Suppl 2:S1-5. doi:10.1111/j.1524-4733.2009.00550.x. 95. Gallego G, Haas M, Hall J, Viney R. Reducing the use of ineffective health care interventions: an Evidence Check rapid review brokered by the Sax Institute (www.saxinstitute.org.au), for the NSW Treasury. 2010. 96. Australian Government Department of Health and Family Services (DHFS). Australia's Commonwealth Department of Health and Family Services, Budget Document 1997-98, Fact Sheet 7: Further steps to ensure sustainable growth in the Pharmaceutical Benefits Scheme. DHFS, Canberra. 1997-98.

http://health.gov.au/internet/main/publishing.nsf/Content/health-pubs-budget97-fact-fact7.htm. Accessed 28 November 2014.

97. Australian Government Department of Health (DoH). Post-market Review of Products Used in the Management of Diabetes. DoH, Canberra. 2015. http://www.pbs.gov.au/info/reviews/diabetes. Accessed 6 January 2015.

98. Australian Government Department of Health (DoH). Post-market Review of Pharmaceutical Benefits Scheme Medicines Used to Treat Asthma in Children. DoH, Canberra. 2015.

http://www.pbs.gov.au/info/reviews/asthma-children-reviews. Accessed 6 January 2015.

99. Australian Government Department of Health (DoH). Post-market Review of the Life Saving Drugs Programme (LSDP). DoH, Canberra. 2015. http://www.pbs.gov.au/info/reviews/life-saving-drugs. Accessed 20 January 2015.

100. Australian Government Department of Health (DoH). Schedule of Pharmaceutical Benefits, effective 1 January 2015 - 31 January 2015. Canberra: DoH; 2015.

101. Australian Government Department of Health and Ageing (DoHA). The impact of PBS reform: report to parliament on the National Health Amendment (Pharmaceutical Benefits Scheme) Act 2007. Canberra: DoHA; 2010.

102. National Prescribing Service. Generic medicines are an equal choice, media release. NPS, Sydney. 2008. http://www.nps.org.au/_data/assets/pdf_file/0007/65527/Generic_medicines_are an_equal_choice.pdf. Accessed 26 October 2011.

103. Medicare Australia. Practice incentives program: quality prescribing incentive guidelines. Canberra: Australian Department of Human Services; August 2011.

104. Pharmaceutical Benefits Pricing Authority. Policies, procedures and methods used in the recommendations for pricing of pharmaceutical products. Canberra: DoHA; 2009.

105. Australian Government Department of Health and Ageing (DoHA). Weighted Average Monthly Treatment Cost (WAMTC) users' manual. Canberra: DoHA; April 2009. 
106. Duckett S, Willcox S. The Australian Health Care System. 4th ed. South Melbourne: Oxford University Press; 2011.

107. Australian Government Department of Health and Ageing (DoHA). Memorandum of Understanding between Medicines Australia and the Commonwealth of Australia. Canberra: DoHA; 6 May 2010.

108. Australian Government Department of Health and Ageing (DoHA). Pharmaceutical Benefits Scheme price disclosure: business rules. Canberra: DoHA; July 2007.

109. Australian Government Department of Health and Ageing (DoHA). Expanded and accelerated price disclosure: what's new? What's different? Canberra: DoHA; November 2010.

110. Medicare Australia. Bulletin Board, Autumn 2009. Canberra: Medicare Australia; 2009.

111. Viellaris R. Leftover drugs to be used on chemotherapy patients. The Courier-Mail. 2009.

112. Clinical Oncological Society of Australia and Medical Oncology Group of Australia and Haematology Society of Australia and New Zealand and Private Cancer Physicians of Australia. Joint position statement on intravenous chemotherapy supply program (ICSP) budget measure 2008. 2009.

http://www.cosa.org.au/cosa_assets/files/About $\% 20 \mathrm{us} \% 20$ -

\%20publications/Intravenous\%20Chemotherapy\%20Supply\%20Program.pdf.

113. Department of Health and Ageing. Factsheet for the Efficient Funding of Chemotherapy Drugs. 2012. http://www.pbs.gov.au/info/publication/factsheets/shared/revised-arrangements-for-chemotherapy. Accessed 3 April 2012.

114. Ensor T. Transition to universal coverage in developing countries. In: Carrin G, Buse K, Heggenhougen K, Quah S, editors. Health Systems Policy, Finance and Organization. Oxford: Elsevier / Academic Press; 2009.

115. New Zealand Public Health and Disability Act 2000, (2000).

116. Pharmaceutical Management Agency (PHARMAC). Pharmaceutical Management Agency Annual Report for the year ended 30 June 2014. New Zealand: PHARMAC; 2014.

117. Grocott R. Applying Programme Budgeting Marginal Analysis in the health sector: 12 years of experience. Expert review of pharmacoeconomics \& outcomes research. 2009;9(2):181-7.

118. Pharmaceutical Management Agency (PHARMAC). PHARMAC Annual Review 1995. New Zealand: PHARMAC; 1995.

119. Pharmaceutical Management Agency (PHARMAC). Notification: Proposal relating to sole supply of blood glucose meters and test strips approved. New Zealand: PHARMAC; 8 August 2012.

120. Allen + Clarke. Evaluation of the implementation of a decision to change the funding and supply of blood glucose meters and test strips. New Zealand: PHARMAC; September 2014. 
Table 1: Search strategy

A MEDLINE/PubMed search was performed on 2 May 2013 for English and French language articles with no date restrictions. Reference lists of relevant articles were pearled for additional material, including from the grey literature.

((unnecessary procedures[mh]) OR (disinvest*[tiab]) OR ("low value"[ti]) OR ("choosing wisely"[tiab])) OR (((health care rationing[mh]) OR (cost control[mh]) OR (health priorities/ec) OR (resource allocation[mh]) OR (technology assessment, biomedical[mh]) OR (biomedical technology/ec) OR (budgets[mh]) OR (investments[mh]) OR (delivery of health care/ec) OR (cost-benefit analysis[mh]) OR (diffusion of innovation[mh]) OR (formularies as topic[mh]) OR (reimbursement mechanisms[mh]) OR (comparative effectiveness research[mh]) OR (decision making[mh]) OR (decision making, organizational[mh]) OR (priority setting[ti]) OR (coverage[ti]) OR (technology[ti]) OR (technologies[ti]) OR ("cost containment"[ti]) OR (rationing[ti]) OR (decision*[ti]) OR (reimburs*[ti]) OR (pmba[ti]) OR ("program budgeting" OR "programme budgeting") OR ("marginal analysis")) AND ((("de-adopt*") OR (deadopt*) OR (delist*[tiab]) OR ("delist*"[tiab]) OR (ineffective[ti]) OR (redeploy*[ti]) OR (divest*[ti]) OR (obsolete[ti]) OR (obsolescen*[ti]) OR (abandon*[ti]) OR (decommission*[ti]) OR ("de-implement*") OR (deimplement*) OR ("phase out"[ti]) OR ("phasing out"[ti]) OR (reinvest[ti]) OR (reinvesting[ti]) OR (reinvestment[ti]) OR (discard*[ti]) OR (reassess*[ti]) OR (reallocat*[ti]) OR (disuse[ti]) OR (unnecessary[ti])) OR (defund*)))

Table 2: Criteria used to identify potential candidates for assessment and disinvestment when conducting active disinvestment reviews

\begin{tabular}{|c|c|c|}
\hline Country, agency & $\begin{array}{c}\text { Identification of potential candidates for } \\
\text { disinvestment }\end{array}$ & $\begin{array}{c}\begin{array}{c}\text { Criteria for assessing candidates for } \\
\text { disinvestment }\end{array} \\
\end{array}$ \\
\hline $\begin{array}{l}\text { Australia, } \\
\text { Pharmaceutical } \\
\text { Benefits Advisory } \\
\text { Committee (PBAC) }\end{array}$ & $\begin{array}{l}\text { Ad-hoc. Drugs considered where there are } \\
\text { concerns regarding: the quality of use; cost } \\
\text { effectiveness; clinical effectiveness; higher } \\
\text { than predicted utilisation; and/or international } \\
\text { differences[28]. }\end{array}$ & $\begin{array}{l}\text { Drugs considered not sufficiently safe, } \\
\text { sufficiently effective, or sufficiently cost- } \\
\text { effective following multiple technology } \\
\text { assessment }\end{array}$ \\
\hline $\begin{array}{l}\text { Canada, Atlantic } \\
\text { Common Drug } \\
\text { Review }\end{array}$ & $\begin{array}{l}\text { Ad-hoc. Drugs considered where there have } \\
\text { been changes in: scientific evidence } \\
\text { regulatory status, cost-effectiveness or budget } \\
\text { impact related to changes in the drug cost or } \\
\text { the cost of its comparators. }\end{array}$ & $\begin{array}{l}\text { Drugs considered not sufficiently safe, } \\
\text { sufficiently effective, or sufficiently cost- } \\
\text { effective following multiple technology } \\
\text { assessment }\end{array}$ \\
\hline $\begin{array}{l}\text { France, Transparency } \\
\text { Commission }\end{array}$ & All listed drugs. & $\begin{array}{l}\text { SMR rating: 1) effectiveness and safety; 2) } \\
\text { availability of alternatives; } 3 \text { ) disease } \\
\text { severity; 4) impact on health of individual; } \\
\text { and 5) impact on public health[27]. Excludes } \\
\text { cost-effectiveness. }\end{array}$ \\
\hline $\begin{array}{l}\text { New Zealand, } \\
\text { Pharmaceutical } \\
\text { Management Agency } \\
\text { (PHARMAC) }\end{array}$ & $\begin{array}{l}\text { Drugs facing price competition where are } \\
\text { alternatives that can deliver the same or } \\
\text { similar health outcomes. }\end{array}$ & Those not delivering value for money. \\
\hline $\begin{array}{l}\text { United Kingdom, } \\
\text { National Institute for } \\
\text { Health and Care } \\
\text { Excellence (NICE) }\end{array}$ & $\begin{array}{l}\text { Any included in NICE cancer service } \\
\text { guidance, clinical guidelines, interventional } \\
\text { procedures and technology appraisals } \\
\text { guidance since } 2007[61,62] . \text { Cochrane } \\
\text { reviews that conclude that interventions } \\
\text { should not be used or could not be } \\
\text { recommended[23, 63, 64]. }\end{array}$ & $\begin{array}{l}\text { Drugs considered not sufficiently safe, } \\
\text { sufficiently effective, or sufficiently cost- } \\
\text { effective following multiple technology } \\
\text { assessment }\end{array}$ \\
\hline
\end{tabular}


Table 3: Tools to encourage prescribing of generics versus originators

\begin{tabular}{|c|c|c|c|c|c|c|}
\hline Country & $\begin{array}{c}\text { Mandatory } \\
\text { writing } \\
\text { prescriptions } \\
\text { using INN }\end{array}$ & $\begin{array}{l}\text { Mandatory } \\
\text { dispensing of } \\
\text { generics }\end{array}$ & $\begin{array}{c}\text { Allowing } \\
\text { pharmacists to } \\
\text { substitute } \\
\text { between } \\
\text { originator and } \\
\text { generic drugs }\end{array}$ & $\begin{array}{l}\text { Dispensing } \\
\text { incentives for } \\
\text { pharmacists }\end{array}$ & $\begin{array}{c}\text { Education or } \\
\text { awareness } \\
\text { campaigns }\end{array}$ & $\begin{array}{l}\text { Prescribing } \\
\text { targets / fund } \\
\text { holding }\end{array}$ \\
\hline Australia & $x$ & $x$ & $\checkmark$ & $\checkmark$ & $\checkmark$ & $x$ \\
\hline Canada & $\begin{array}{l}\text { Varies by } \\
\text { province }\end{array}$ & $\begin{array}{l}\text { Varies by } \\
\text { province }\end{array}$ & $\begin{array}{l}\text { Varies by } \\
\text { province }\end{array}$ & $x$ & $\checkmark$ & $x$ \\
\hline France & $\checkmark$ & $\checkmark$ & $\checkmark$ & $\checkmark$ & $\checkmark$ & $\checkmark$ \\
\hline $\begin{array}{l}\text { New } \\
\text { Zealand }\end{array}$ & $x$ & $\checkmark$ & $x$ & $x$ & $\checkmark$ & $x$ \\
\hline $\begin{array}{l}\text { United } \\
\text { Kingdom }\end{array}$ & $x$ & $x$ & $x$ & $x$ & $\checkmark$ & $\checkmark$ \\
\hline
\end{tabular}

INN: International non-proprietary name

Figure 1: Disinvestment in drugs typology

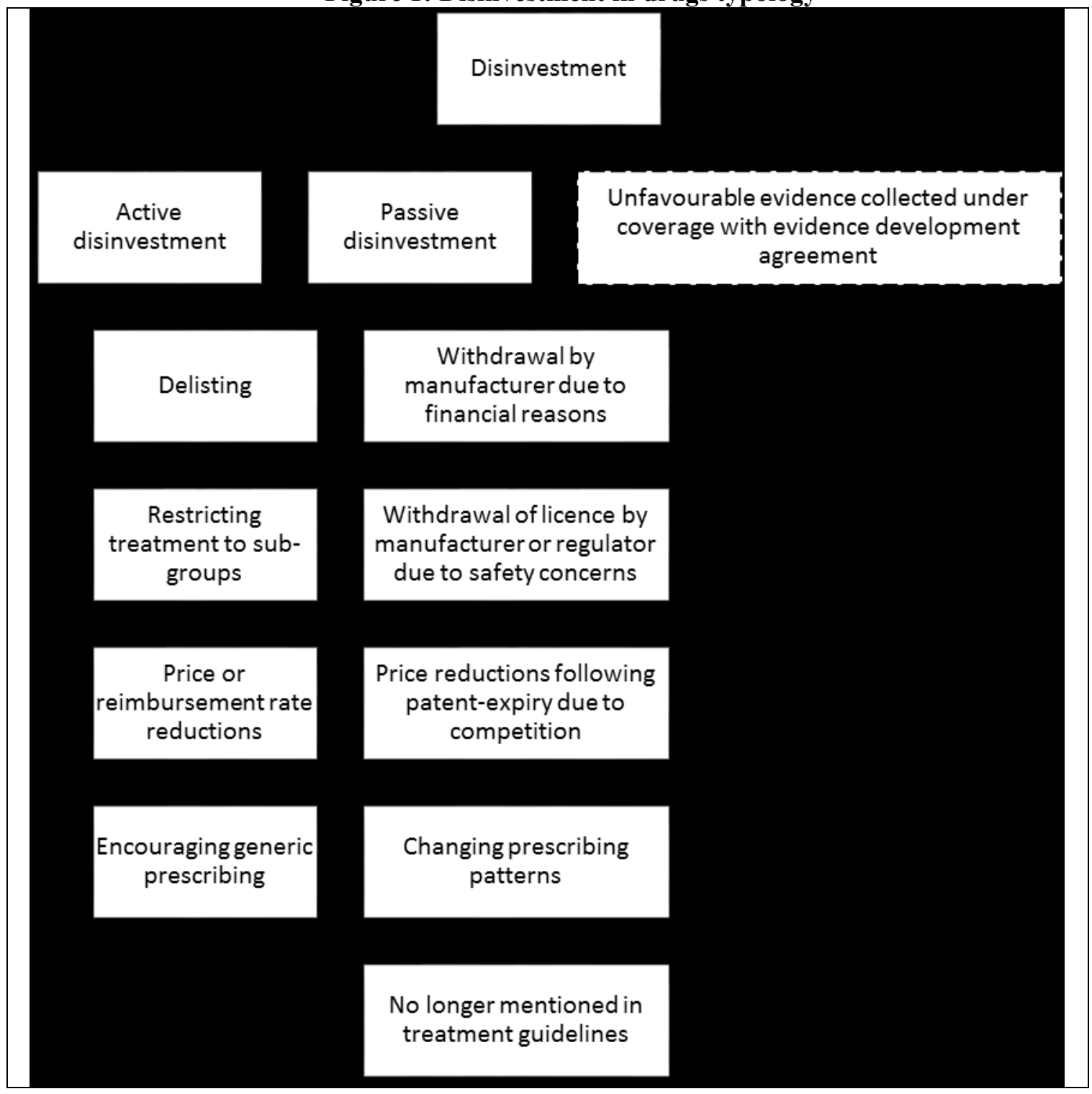


Figure 2: Change in number of Pharmaceutical Schedule listings over time in New Zealand

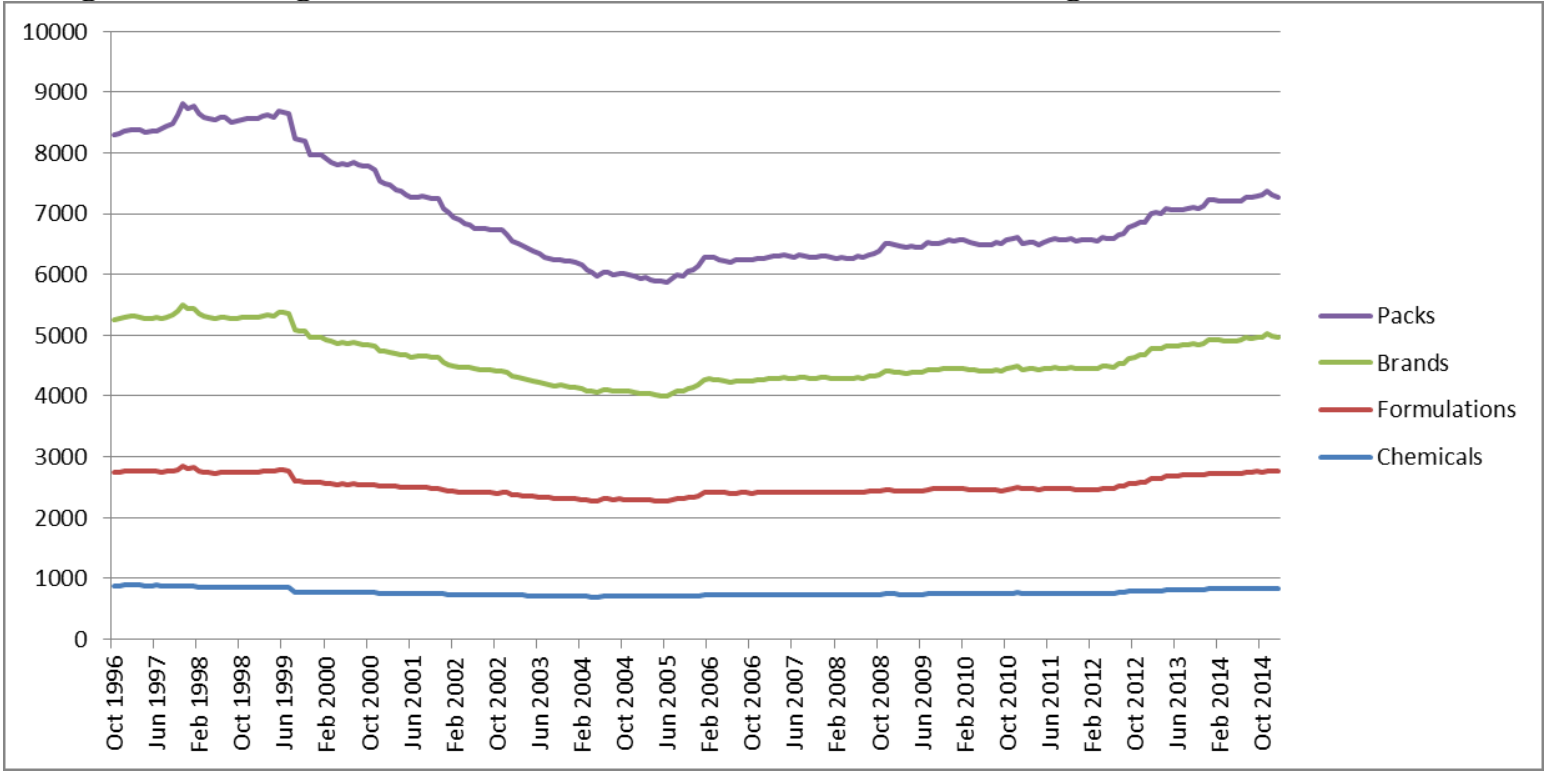

Note: Each chemical (active pharmaceutical ingredient) is provided in multiple formulations, which are supplied under multiple brand names, and offered in a range of pack varieties. Source: [65]. 


\section{Box 1: France}

\section{Broader health and pharmaceutical policy}

The French health care system is of a mixed type, structurally based on a Bismarckian approach with Beveridge goals reflected in the single public payer model, the current increasing importance of tax-based revenue for financing health care and strong state intervention. The Statutory Health Insurance (SHI) (Sécurité Sociale) was established in 1948 and covers currently almost 100\% of the resident population. Financial responsibility for health care in France is mainly borne by SHI. However, SHI only funds around three quarters of health spending, leaving considerable scope for complementary sources of funding such as private supplementary Health Insurances[66].

$67.5 \%$ of total pharmaceutical expenditure (including prescription and OTC drugs) is funded by the Statutory Health Insurance, $1.3 \%$ by the State, $14.3 \%$ by private supplementary Health Insurances and $16.9 \%$ by patients themselves. Only medicines on the 'list of reimbursable drugs' are reimbursed by the SHI. The Transparency Commission assesses a drug's medical value (SMR: service médical rendu) ${ }^{3}$ and improvement in the medical value (ASMR: amélioration du service médical rendu $)^{4}$ in order to decide whether a drug should be included on the list of reimbursable drugs and to set prices. Four criteria are used to assess the SMR rating: 1) seriousness of the pathology/disease in question; 2) effectiveness of the drug and its potential adverse effect profile; 3 ) place of the drug in the therapeutic process in relation to alternatives currently available in France; 4) impact of the drug on public health[67]. Subsequent reimbursement rates varies between $0 \%$ for "no or inadequate therapeutic value', $15 \%$ for low therapeutic value, $35 \%$ for 'moderate therapeutic value and $65 \%$ for 'major or considerable' therapeutic value. In 2012 prescription drugs were reimbursed at an average rate of 70\% by SHI. All or substantially all of the remaining $30 \%$ are covered by private supplementary Health Insurances for the $95 \%$ of the French population having one.

Methods used to identify potential candidates, criteria for assessing candidates, and methods used to implement disinvestment

Disinvestment in drugs has mainly involved delisting and price reductions. From 2000 to 2004, the Transparency Commission comprehensively re-evaluated 4,490 drugs on the market at the time[27]. Drugs with a SMR rating of 'insufficient' $(n=835)$ were subsequently removed from the list of reimbursable drugs, including mucolytics, expectorants, and H2-receptor antagonists[27]. The concept of drugs with 'insufficient medical value' encompassed drugs that had been superseded by newer more effective drugs; drugs considered dangerous; and drugs no longer considered effective. Economic considerations were not a major concern in the process. At the same time, 840 other drugs received a SMR rating of 'moderate or low medical value'. As a consequence the reimbursement rate of 617 products was reduced from $65 \%$ to $35 \%$, which impacted drugs such as analgesics, antihistamines, antiseptics, and antifungals[27]. The changes in ratings were heavily contested by the industry. As a result, 763 of the drugs that were rated as 'insufficient' were re-evaluated in three waves

\footnotetext{
${ }^{3}$ If the SMR is "major or considerable", "moderate" or "low but nevertheless justifying reimbursement" it can be included in the list of reimbursable drugs, while drugs rated as 'insufficient' or 'of low medical benefit' are not covered.

${ }^{4}$ The ASMR is rated in comparison with the other drugs already available in the same therapeutic area on a scale from I to V, with ASMR-I being given to a drug providing a major improvement and ASMR-V to drugs providing no or inadequate improvement.
} 
between 2003 and 2006, although 525 were confirmed as insufficient and subsequently delisted[27]. In 2010, the reimbursement rate for drugs with "low medical value" was lowered to $15 \%$ resulting in the re-assessment of those drugs in order to confirm the SMR rating.

Following the review in 2000-2004, three different processes were put into place[68]. First, the Transparency Commission conducts a systematic re-assessment five years after the drug is first listed on the list of reimbursable medicines. This includes a re-assessment of the SMR taking into account any new evidence available. Second, the Transparency Commission may conduct a re-assessment of a therapeutic class. The reasons for a class re-assessment are: a lack of data on efficacy at the time of the first assessment, or the introduction of the new reimbursement rate of $15 \%$. Finally, a single drug may be assessed for the same reasons as before. The latter two processes may be initiated by the Ministry of Health or by the Transparency Commission.

As for other countries, safety issues have been another reason for disinvestment in France. The most wellknown example in recent years was the case of benfluorex, a drug indicated for the management of overweight in patients with type 2 diabetes mellitus or as adjunct to diet in hypertriglyceridemia and widely used off-label for treating obesity. On the market in France since 1987, benfluorex was re-evaluated in 1999 and rated as being of 'insufficient medical value'. This decision was challenged by the firm leading to a second evaluation in 2006 which was inconclusive and allowed benfluorex to keep its reimbursement rate of $65 \%$ [69]. Finally benfluorex was withdrawn from the market in November 2009 after the discovering of severe cardiac complications[70]. Occasionally disinvestment due to safety issues has gone beyond the recommendations of the European Medicine Agency (EMA). This was the case for pioglitazone which was withdrawn from the market in France while EMA authorized the drug with a warning on safety[71].

France has also introduced a range of measures in order to enhance the utilization of generics versus originators: allowing pharmacists to substitute between originator and generic drugs was introduced in 1999; voluntary INN prescribing was introduced in $2002^{5}$; and a pay-for-performance scheme (ROSP: 'rémunération sur objectifs de santé publique') was extended to include prescribing targets for generic prescriptions for statins, antibiotics, treatments for hypertension etc in 2012. More recently, mandatory INN prescribing was introduced in 2015 after certification of all medical software.

Other measures have also been introduced in order to decrease the cost of generic drugs, including: a reference pricing scheme introduced in 2013, where a reference prices for each generic group is based on the average prices of the generics in the French market (TFR: Tarif forfaitaire de responsabilité); and mandatory price reductions following the introduction of a generic $\operatorname{drug}^{6}$. The aim of these policies was to convince physicians to switch as much prescriptions as possible from the originators to their generic counterparts[27].

\section{Box 2: United Kingdom}

Broader health and pharmaceutical policy

\footnotetext{
${ }^{5}$ Before 1999 INN prescribing was not allowed.

${ }^{6}$ When the first generic enters the market the price of the originator drops by $20 \%$, and the price of the generic is fixed $60 \%$ lower than the initial price of the originator. 18 months after, the price of the originator decreases again by $12.5 \%$ and the price of the generics drops by $7 \%$. TFR is introduced if the substitution rate by pharmacists is lower than $80 \%$.
} 
In the United Kingdom (UK) when the National Health Service (NHS) was established in 1948 the founding principles were that: it should be free at the point of delivery and based on clinical need, not ability to pay. Funded by the tax-payers, the NHS meant that access to drugs was no longer limited by income. Community pharmacists dispensing drugs are reimbursed by the NHS Prescription Services, with the payment schedule based on average wholesale prices and calculated by the NHS Business Services Authority and published as the monthly Drug Tariff ${ }^{7}$. Generally general practitioners are able to prescribe whatever they deem appropriate, however the Drug Tariff contains a 'blacklist'[72], which lists the drugs and/or specific brands of drugs that cannot be prescribed on NHS primary care prescriptions. The NHS Prescription Services will not refund the cost of drugs on the 'blacklist' to the dispensing pharmacy. Whilst the legislation exists, in practice its use is generally limited to non-controversial prescribing of branded products that can be purchased over the counter. There are concerns relating to the validity of this national legislation in the face of EU anti-competition rules. There are also concerns that the 'blacklist' would threaten the autonomy of prescribers. Consequently policy makers have used other mechanisms to influence prescribing.

From 1991, in order to control risking NHS deficits, the UK Government introduced policies to make regional health authorities and providers more responsible for budgets, eventually resulting in the creation of purchasing units (primary care trusts)[73, 74]. This strategy inevitably introduced the need for regional drug and therapeutics committees and arrangements to provide advice regarding which drugs were funded. While successful at reducing the growth in pharmaceutical expenditure[74], one unintended consequence of this devolution of authority and fixed budgets was the 'post code lottery' whereby patients access to treatments, especially high cost treatments, was determined by where they lived.

In response to this situation, in 1999 a new special health authority, the National Institute for Clinical Excellence (NICE) ${ }^{8}$ was created[75]. NICE's remit was to introduce 'evidence based medicine' into routine practice and achieving improvements in the quality and delivery of care through outcome measurement. NICE's remit is primarily England and Wales but some products are also used by Scotland and Ireland. NICE's clinical guidelines programme includes making recommendations about the on and off-label usage of drugs. The most high-profile programme of the NICE portfolio is the technology appraisal process, which looks at the clinical and cost-effectiveness of drugs. Focusing on how they perform in practice and how much it costs for one additional quality adjusted life year. Similar organisations exist in both Scotland (Scottish Medicines Consortium, SMC)[76] and Wales (All Wales Medicines Strategy Group, AWMSG)[77].

While negative recommendations from NICE are voluntary and it does not mean that a drug cannot be prescribed by a clinician or funded by the NHS, a positive recommendation means that local NHS bodies must fund these technologies within three months[78]. However concerns have been raised that these positive recommendations are diverting resources away from other, perhaps more cost-effective, drugs or health programmes due to a lack of headroom[79].

Methods used to identify potential candidates, criteria for assessing candidates, and methods used to implement disinvestment

\footnotetext{
${ }^{7}$ The arrangements for secondary care are left to individual institutions with usage and purchasing being negotiated by the healthcare professionals employed by that organisation.

${ }^{8}$ Now the National Institute for Health and Care Excellence.
} 
Since 2006, NICE has had an active disinvestment programme[23, 63]. Initially a pilot active disinvestment programme was introduced that aimed to identify low value drug and non-drug interventions, which if stopped, would save over GBP£1m each[23, 63]. However NICE concluded that there were few identifiable candidates for total disinvestment (i.e. 'blacklisting'), that the emphasis should be placed on better targeting of treatments, and that NICE was already identifying candidates for disinvestment through its existing processes (e.g. through clinical guidelines)[23]. Consequently NICE continued to identify candidates for disinvestment through its existing processes and publishes 'recommendation reminders', reiterating existing guidance. In particular, following the launch of the Department of Health's Quality, Productivity and Prevention (QIPP) programme, NICE reviewed its 'disinvestment programme' and launched a database of 'do not do's' (replacing the 'recommendation reminders')[23, 63, 61]. The database contains all the 'do not do' recommendations contained in NICE cancer service guidance, clinical guidelines, interventional procedures and technology appraisals guidance since 2007[61, 62]. Working with the UK Cochrane Centre, NICE has also developed summaries of newly published Cochrane reviews that conclude that interventions should not be used or could not be recommended[23, 63, 64].

The UK Government has also introduced a range of measures in order to encourage the utilisation of generics versus originators, as well as generic drugs that are considered therapeutically-equivalent to a patented drug. This has been achieved nationally through the Quality, Productivity and Prevention (QIPP) programme and the Better Care, Better Value (BCBV) initiatives, in addition to local initiatives[40, 80, 48, 81]. For example, there have been multiple initiatives across Scotland to increase the prescribing of generic angiotensin converting enzyme inhibitors (ACEIs), proton pump inhibitors (PPIs) and statins, including regional formularies, general monitoring of prescribing patterns, benchmarking, academic detailing, and practice based financial incentive schemes[40, 48]. Primary Care groups in England have also successfully introduced similar multiple measures to enhance prescribing efficiency for these three classes[48, 82, 83]. Finally, clinicians are encouraged to prescribe by INN in UK medical schools[40, 83-85].

\section{Box 3: Canada}

Broader health and pharmaceutical policy

Canada has a single-payer, publicly-funded, universal healthcare system. Its existence was established in 1946 beginning in one province (Saskatchewan) with establishment across all provinces in 1966 with the introduction of the Medical Care Act ${ }^{9}$. The healthcare system is largely focussed on acute care delivery; essentially all services delivered within a hospital setting are publicly funded. In the outpatient and community setting, no point-of-contact payment is allowed. However, publicly-funded drug and outpatient services coverage varies by province. Funding is shared by both the national and provincial governments with the exact funding mix varying over time.

\footnotetext{
${ }^{9}$ In 1984, the Canada Health Act outlined the basic tenancy of the healthcare system establishing the underlying foundational principles of comprehensiveness, universality, portability, accessibility and public administration. Comprehensiveness establishes that all basic medical needs must be covered while universality and portability ensure that all citizens have are covered in all provinces regardless of their home province. Accessibility ensures that all citizens have reasonable access to the system and the tenant of public administration reconfirms Canada's commitment to a public healthcare system.
} 
Canada has no national publicly funded drug insurance plan. A national process exists to critically assess the clinical, economic and patient evidence for new drugs (the Common Drug Review at the Canadian Agency for Drugs and Technologies in Health (CADTH))[86]. The Common Drug Review is advisory to the provinces who make the final reimbursement decision. However, no national process exists to assess or reassess the evidence for drugs already publicly available. The current disinvestment (de-listing) landscape is haphazard and responsive; provinces must develop their own individual processes to support disinvestment activities for drugs.

Methods used to identify potential candidates, criteria for assessing candidates, and methods used to implement disinvestment

The most developed disinvestment process is that of the Atlantic provinces (Prince Edward island, Newfoundland and Labrador, Nova Scotia and New Brunswick)[29]. An explicit review mechanism exists through the Atlantic Common Drug Review. While this review process may result in disinvestment, the arching goal of the process is to ensure that the drugs covered are current and based on best available evidence. A review may be launched in response to changes in the scientific evidence, regulatory status, cost-effectiveness or budget impact related to changes in the drug cost or the cost of its comparators. Importantly, this process results in recommendations to the provincially funded drug plans in Atlantic Canada with each province making their own decisions. Ontario has adopted a different strategic approach. In 2011, Ontario's Citizen's Council was asked to deliberate on an approach to managing the drug formulary[87]. Specifically, the council was asked "Under what conditions should the executive officer of the Ontario public drug programs consider delisting of drug products on the Ontario formulary?". The Council outlined the need for a formal clear, transparent disinvestment process based on evidence with both timelines and milestones. Suggested criteria for review included aspects such as cost, availability of bio-equivalents, and efficacy. The implementation of a process in response to the Council's deliberation is unclear. Disinvestment processes within the other provinces may occur in one-off fashion with periodic refreshes to the formularies.

Disinvestment in the form of delisting drugs is very uncommon. More common, is the targeting of utilisation patterns of drugs. For example, in 2013 the provincial Government in Alberta made changes to the pricing of generics to cover only $18 \%$ of the brand name price[88]. This change in prices was accompanied by a public campaign to encourage patients to ask for generics in order to increase the prescription of generic drugs. The success has yet to be evaluated.

A range of measures in order to enhance the utilization of generics have also been introduced, such as educational material targeted towards physicians accompanied by a major public campaign.

\section{Box 4: Australia}

Broader health and pharmaceutical policy

The Commonwealth Government of Australia has subsidised access to drugs since 1948 via the Pharmaceutical Benefits Scheme (PBS) [89]. Through the PBS, the Commonwealth Government aims to provide affordable, timely and equitable access to necessary drugs to Australian patients at an affordable cost to the Government. 
The PBS is one of three pillars of the Australian health system, the other two being free treatment in public hospitals and subsidised out-of-hospital medical services through Medicare.

The PBS provides reimbursement for medicines prescribed in the community and dispensed by community pharmacies, as well as some drugs dispensed in private hospitals, and some drugs dispensed at public hospitals or specialist treatment centres (i.e. Section 100 drugs). In 2005 59\% of items listed on the PBS schedule were restricted in some form and $27 \%$ of PBS items were subject to authority-required restrictions[90].

The Pharmaceutical Benefits Advisory Committee (PBAC) makes recommendations regarding which drugs should be listed on the PBS schedule and which vaccines should be listed on the National Immunisation Programme (NIP) schedule[91]. The PBAC is required to consider[92, 93]: "the [clinical] effectiveness and cost of therapy involving the use of the drug, preparation or class, including by comparing the effectiveness and cost of that therapy with that of alternative therapies, whether or not involving the use of other drugs or preparations." In 1993, Australia became one of the first countries to require that an economic evaluation form part of the evidence submitted when considering the funding of a new drug[94].

Methods used to identify potential candidates, criteria for assessing candidates, and methods used to implement disinvestment

Traditionally, delisting drugs from the PBS has been largely confined to: withdrawal by a manufacturer for reasons other than safety concerns[95]; delisting due to withdrawal of market approval by the Therapeutics Goods Administration, usually on safety grounds (eg. rofecoxib in 2004); and delisting after the drug is rescheduled and becomes available for purchase over the counter (e.g. anti-fungal creams in 1997-98)[95, 96]. This is primarily because the PBAC has traditionally been passive, considering applications submitted to it, usually by manufacturers seeking PBS-listing of new drugs (or new indications), rather than proactively reviewing drugs already on the formulary. Thus instead of active disinvestment and delisting, it is ultimately prescribers who elect to cease prescribing treatments they consider to be less effective or more toxic compared to more recently PBS-listed drugs.

This has changed recently with the PBAC conducting a series of post-market reviews of PBS-listed drugs. These reviews have been initiated due to 'concerns related to the quality use of a medicine, cost effectiveness, clinical effectiveness, higher than predicted utilisation and/or international differences in utilisation[28]. These reviews may be initiated by PBAC or by referral from the Minister for Health. Reviews have been conducted for the following classes of drugs: biological disease-modifying anti-rheumatic drugs (bDMARDs)[42], treatments for Alzheimer's Disease[31], and anticoagulation therapies[36], and are currently in the process for: products used in the management of diabetes[97], treatments for asthma in children[98], and the life-saving drugs programme[99 $]^{10}$.

These post-market reviews have resulted in a number of recommendations to ensure the cost-effectiveness of a PBS-listed drug in clinical practice. In some cases this disinvestment took the form of requiring a price reduction. For example, as a result of the review of treatments for Alzheimer's Disease, the PBAC recommended that none of the PBS-listed drugs under review should be delisted, but a $40 \%$ price reduction be applied[31]. Similarly, as a result of the review of bDMARDs the PBAC also recommended a price reduction,

\footnotetext{
${ }^{10}$ A programme separate to the PBS which subsidises expensive life-saving drugs for very rare life-threatening conditions.
} 
however the manufacturer of anakinra did not agree to the new price and the product was withdrawn by the manufacturer[41, 42]. In other cases this disinvestment took the form of restricting treatment to certain patients. For example, the review of anticoagulation therapies to treat atrial fibrillation recommended restricting new oral anticoagulants (NOACs) to 'patients unable to tolerate warfarin therapy and/or who are unable to obtain satisfactory international normalised ratio (INR) control despite specific measures'[36]. This restriction is yet to be implemented ${ }^{11}[100]$.

Over the past 20 years Australia has also introduced a range of measures to enhance the utilization of generics versus originators, such as: permitting brand substitution by pharmacists even if the prescription specifies a particular brand, unless the prescriber indicates that "brand substitution is not permitted" and subject to the patient's agreement[49], paying pharmacists an incentive to dispense a benchmark-priced off-patent medicine[101], increasing consumer awareness of generics[102], and addressing the concerns of clinicians regarding generics through 'academic detailing'[103]. Australia has also implemented measures to reduce the prices paid for generic drugs, such as reference pricing[104-106] and mandatory price discounts[101, 107]. More recently 'price disclosure rules' have been introduced under which manufacturers must provide information about the actual transaction prices to pharmacies, including any non-price incentives such as bonus stock or in-kind discounts[108, 109, 107]. If the weighted average disclosed price is more than $10 \%$ lower than the PBS price then the PBS price is reduced to the weighted average disclosed price. These latter reforms appear to have been particularly effective in reducing the PBS prices of drugs for which generic versions are available[45].

Finally, in order to minimise the cost of intravenous chemotherapies, the Department of Health proposed introducing the Intravenous Chemotherapy Supply Program (ICSP) whereby pharmacists are reimbursed for the amount of drug used, rather than the number of vials dispensed[110]. This was met with criticism regarding the potential for under-prescribing or under-dosing of some high cost drugs and higher costs for the patient or the hospital[111, 112]. Consequently ICSP was not implemented and the Efficient Funding of Chemotherapy Drugs (EFCD) initiative (Revised Arrangements) was introduced from 2011 whereby pharmacists are reimbursed for the combination of vials that most cost effectively comprises the required patient dose[113].

\section{Box 5: New Zealand}

\section{Broader health and pharmaceutical policy}

Drugs in New Zealand have received public funding since 1941[114]. The New Zealand Pharmaceutical Management Agency (PHARMAC) is the Government Agency that determines which drugs will be listed on the Pharmaceutical Schedule, and thus receive publicly funding, and under what conditions. The New Zealand Public Health and Disability Act 2000 states[115]:

"[PHARMAC is] to secure for eligible people in need of pharmaceuticals, the best health outcomes that are reasonably achievable from pharmaceutical treatment and from within the amount of funding provided ..."

\footnotetext{
${ }^{11}$ The current restriction for dabigatran is: Patient must have one or more of the following risk factors for developing stroke or systemic embolism: (i) Prior stroke (ischaemic or unknown type), transient ischaemic attack or non-central nervous system (CNS) systemic embolism; (ii) age 75 years or older; (iii) hypertension; (iv) diabetes mellitus; or (v) heart failure and/or left ventricular ejection fraction
} $35 \%$ or less. 
Thus PHARMAC must meet the budget set for it by the Minister of Health, and in doing so it must seek to optimise health outcomes. PHARMAC's budget for 2013/14 was set at NZ\$795 million to cover community drugs and devices, vaccines, and hospital-administered cancer treatments[116].

PHARMAC makes changes to the Pharmaceutical Schedule to achieve this objective. These changes may take the form of: listing new drugs; subsidy/price reductions; and responding to supply market activity (e.g. global product discontinuations). Furthermore, in the year to 30 June 2014, 4.3\% of prescriptions were subject to a prospectively obtained Special Authority authorisation[116].

The defined annual budget and its anticipated future pathway constrain PHARMAC's ability to fund new drugs, and consequently it is incentivised to make careful choices, ensuring that each decision at the margin offers the best value in terms of health outcomes. Effectively PHARMAC uses a programme-budgeting and marginal analysis (PBMA) approach to adoption of new drugs[117]. PHARMAC considers nine criteria ${ }^{12}$ when considering listing a drug, including effectiveness, safety, costs and cost-effectiveness[65]. These criteria are considered relative to all the funding options available at a given time.

Methods used to identify potential candidates, criteria for assessing candidates, and methods used to implement disinvestment

PHARMAC focuses on price reductions to improve the value for money for existing technology and make headroom for listing new drugs. Price reductions generally arise as a result of competition, which is enabled where there are alternatives that can deliver the same or similar health outcomes. As a 'buyer' of health outcomes PHARMAC has utilised a range of tools to create competitive environments for the supply drugs, but at improved value, including[47]:

- Rebates and discounts (e.g. price-volume agreements);

- Package agreements (e.g. listing a new drug that is not cost-effective at the posted international price if the manufacturer agrees to discount one or more of its other currently listed drugs);

- Tendering sole supply for off-patent drugs;

- Reference pricing therapeutically equivalent on-patent and off-patent drugs; and

- Contracts (e.g. agreements to exchange a current price reduction for protection against the future use of other cost-saving tools).

PHARMAC's savings activity each year creates new price concessions of around 6-7\% of the value of the entire portfolio. These savings along with modest rises of budget of about 3\% p.a. on average over the 21-year period of PHARMAC's existence[116, 118] have been sufficient to manage growth in both volume, and the mix of treatments used including adoption of more expensive new technologies[116].

\footnotetext{
${ }^{12}$ 1) the health needs of all eligible people within New Zealand; 2) the particular health needs of Maori and Pacific peoples; 3) the availability and suitability of existing drugs, therapeutic medical devices and related products and related things; 4) the clinical benefits and risks of pharmaceuticals; 5) the cost-effectiveness of meeting health needs by funding pharmaceuticals rather than using other publicly funded health and disability support services; 5) the budgetary impact of any changes to the Pharmaceutical Schedule; 6) the direct cost to health service users; 7) the Government's priorities for health funding, as set out in any objectives notified by the Crown to PHARMAC, or in PHARMAC's Funding Agreement, or elsewhere; and 8) such other criteria as PHARMAC thinks fit
} 
The effect of these policies in PHARMAC's early years was a reduced range of varieties of drugs (substantially brands, and pack options) (Figure 2). That is, some disinvestment in the form of delisting occurred[65]. The 2012 example of blood glucose testing equipment is an example of how such disinvestment occurs, whilst maintaining access to the health outcomes. PHARMAC moved from a funded range of six blood glucose meters and test strips provided by four suppliers, to a range of three from a single supplier. This resulted in a saving around $\$ 10$ million each year from a baseline spend of about $\$ 22$ million. Around 120,000 patients needed to change product in order to retain their funding, or otherwise would have had to pay out-of-pocket[119, 120]. However, delisting is typically not undertaken because, in the context of falling prices of existing drugs and the increasing asking prices of new ones, past funding decisions are typically better value for money than current decisions.

\section{Author contributions}

Bonny Parkinson and Adam Elshaug contributed to the conception and developed the structure of the paper. The initial systematic review was conducted by Moni Choudhury. All co-authors contributed to the acquisition of information about the policy situation in their respective countries. Bonny Parkinson was responsible for compiling each country's contribution to the paper. All co-authors contributed towards drafting and revising the intellectual content of the manuscript, and approved the final version for publication. Associate Professor Adam Elshaug is the guarantor for the overall content. We are indebted to the anonymous reviewers whose comments greatly improved this paper. An astute summary observation made by reviewer two has been adapted and included in the conclusion section. We acknowledge this input and thank him/her for allowing its inclusion. 